\title{
Cardiotoxicity among Children Accidentally Exposed to Organophosphate Insecticides Coupled with Scorpion Bites in Gaza
}

\author{
Yasser El-Nahhal ${ }^{1 *}$, Ibrahim El-Nahhal ${ }^{2}$ \\ ${ }^{1}$ Department of Earth and Environmental Science Faculty of Science, Islamic University of Gaza, Gaza, Palestine \\ ${ }^{2}$ Université de Toulon, Toulon, France \\ Email: *y_el_nahhal@hotmail.com
}

How to cite this paper: El-Nahhal, Y. and El-Nahhal, I. (2021) Cardiotoxicity among Children Accidentally Exposed to Organophosphate Insecticides Coupled with Scorpion Bites in Gaza. Health, 13, 1045-1063. https://doi.org/10.4236/health.2021.139078

Received: August 18, 2021

Accepted: September 19, 2021

Published: September 22, 2021

Copyright $\odot 2021$ by author(s) and Scientific Research Publishing Inc. This work is licensed under the Creative Commons Attribution International License (CC BY 4.0).

http://creativecommons.org/licenses/by/4.0/

\begin{abstract}
Insecticides are toxic chemicals used at homes for controlling insects of public health importance and controlling agricultural pests at home gardens. Their application may result in accidental poisoning. Four accidental insecticide-poisoning children coupled with a scorpion bitten child were brought to the main hospital in southern Gaza for medical treatment. Primary investigation showed severe breath shortness, low heartbeat, and low blood pressure (hypotension). These symptoms are indications of potential cardiotoxicity among children. Electrocardiograms were measured and indicated various heart complications between cases. Complete blood count (CBC) determination showed the highest white blood cells (WBC) in the scorpion-bitted child suggesting the development of immune defense system. Blood electrolyte $\left(\mathrm{Na}^{+}, \mathrm{K}^{+}, \mathrm{Ca}^{2+}\right)$ concentrations indicated disturbances due to poisoning. An interesting outcome of the study is the dramatic alteration in blood glucose concentration. Additionally, activity of acetylcholinesterase (AChE) indicated normal activity in poisoning case 1, moderate inhibition in poisoning case 2 and case 3, normal activity in poisoning case 4 and severe inhibition in poisoning case 5. The levels of Aminotransferase (ALT) and Aspartate Aminotransferase (AST) were within the acceptable range whereas the level of Alkaline Phosphatase (ALP) was above the acceptable reference range suggesting potential Hepato-toxicity. Scorpion bitten child did not receive atropine whereas two poisoned cases were successfully cured by atropine injection. Additionally, alternative safe medical management may be used for cardiotoxicity using vitamin $\mathrm{C}$, vitamin $\mathrm{E}$, quercetin, and curcumin. These vitamins may be recommended as alternative medical treatments for cardiotoxicity.
\end{abstract}




\section{Keywords}

Component, Insecticides, Cardiotoxicity, Children, Scorpion Bites

\section{Introduction}

The use of insecticides at homes has progressively increased due to public health and home garden pests control. In general, houseflies, mosquitoes, several types of cockroaches require adequate control to reduce the population of these insects. Additionally, beetles, fruit fly and mites require frequent application of insecticides to protect the garden. In general, insecticides are being used at home for the above-mentioned purposes. For instance, chlorpyrifos and malathion (organophosphorus insecticides) are currently in use in Gaza to control household and agricultural insects [1]-[6]. Many of these pesticides have been shown to cause cardiotoxicity worldwide [7], reproductive toxicity [8] and carcinogenetic disturbances worldwide [9].

Previous investigation showed that farmers used empty pesticide container as domestic tools, resulting in slightly or severely poisoning cases that required medical treatment [10].

So far, tremendous work has been conducted to reduce the potential occurrence of occupational or accidental poisoning. This includes, pesticides educational programs, development of friendly pesticide formulations and changing pesticide application [11] [12] [13] [14] [15], using alternative and management methods [16] [17] [18] [19]. These efforts succeeded in some locations and failed in other locations due to misleading information. In general, poisoning occurred each year but the irregular issue is that children are brought to the hospital with a common complaint of cardiac arrest. The objectives of this study are to highlight the cardiotoxicity of insecticides among poisoning children with different toxic substances and evaluate the effectiveness of ameliorating agents as suitable clinical nutritional materials.

\section{Materials and Methods}

\subsection{Management Protocol of Poisoned Cases}

Poisoning cases may be managed according to the following medical protocol, which consists of the following steps.

1) Complete water bath to the child to remove any residue from the surface of the body.

2) Gastric lavage (GL) for conscious cases start with a saline solution (0.9\%) containing active charcoal, followed by milk gavage in some cases. Then the last gastric lavage includes saline solution only. However, unconscious cases are proceeded to the next step without GL.

3) Primary heart test includes recording blood pressure (BP), heartbeat (HB), 
and breathing mode. Low records of these parameters are alerts of cardiotoxicity.

4) Clinical observations such as Anorexia, Blurry vision, Body secretions, Confusion, Convulsion, Diarrhea, Headache, Irregular heartbeat, Mucous, Nausea, Pain, Respiratory depression, Saliva, Sensation, Sweeting, Tears, Tingling, Unconsciousness, Very narrowed pupils, vomiting, weakness.

5) Complete blood count (CBC), liver function test (Alanine Aminotransferase (ALT) Aspartate Aminotransferase (AST) Alkaline Phosphatase (ALP)), and kidney biomarkers (Urea, and creatinine), and neurotransmitter test (Acetylcholinesterase (AChE)).

6) Data collection. In this section, the parents of the poisoned case provided the following information. Detailed home address, job of parents, pest control system at home, and at garden. Family members, previous number of poisoning.

7) Medical treatment. This step relies on data obtained from blood analysis and from the clinical symptoms.

If the level of AChE activity is very low, this indicates severe inhibition of the enzyme. Accordingly, atropine $0.1 \mathrm{mg} /(2-3$ ampoule/II hours $)$ can be given to the corresponding case each 6 hour taking into account the response of eye to light. As the eye responded positively to light, this indicates the successful activity of atropine to recover the poisoning case. If the eye weakly responded, this suggests that Atropine is not effective as an antidote. Following atropine injection, the level of AChE activity is monitored, if there is a rise in the enzyme level this suggests that atropine injection is detoxifying the case, if not, atropine injection should be changed by Obedoxim or any other successful organophosphates antidote. After recovery of poisoning symptoms, a child can be treated systematically to cure other related symptoms. If the case becomes stable for $24 \mathrm{~h}$, the child may be released from the hospital.

\subsection{Measurement of Enzyme Activity}

The blood samples $(2 \mathrm{ml})$ were collected and analyzed in the same day for the parameters shown below. Acetylcholine esterase activity (AChE) was measured by a spectrophotometer according to the method developed previously by Ellman et al. [20] using acetyl thiocholine iodide as a substrate. The yellow color produced by the reaction was determined at $420 \mathrm{~nm}$. Furthermore, activity of ALP was determined according to Bessey et al. method [21], whereas AST and ALT activities were measured by the procedure of Yan et al. [22] using a commercially available kit from Bio-Merieux. On the other hand urea, creatinine and uric acid were determined using commercially available kits. Additionally, blood sugar concentration was measured using a device called a continuous glucose monitor (CGM). Similarly, blood Electrolyte measurement was conducted using Micro Lab Electrolyte Analyzer $\mathrm{Na} / \mathrm{K} / \mathrm{Cl}$, for Laboratory Panel; and finally complete blood count $(\mathrm{CBC})$ was done using the standard method for routine analysis. 


\subsection{Statistical Analysis}

Average and standard deviation were calculated for the samples collected and measured in the same day, alternatively, the measured data were compared to the corresponding value of the reference dose.

\section{Results and Discussion}

\subsection{Descriptive Observation and Background of the Poisoned Cases}

Five poisoning cases, five children, one male and four females came to the main hospital in southern Gaza, suffering from organophosphate poisoning and one of them suffered from scorpion bite. Collecting the information from children parents indicates that the children were poisoned with different insecticides along with a scorpion bitten child. Figure 1 shows chemical structure, name of poisoning materials and toxicity class of each poison. It is clear that the poisoning materials are organophosphate insecticides. These poisoning materials are Tetraethyl pyrophosphate, Methamidophos, Chlorpyrifos and Malathion. These compounds belong to the following toxicity classes: extremely toxic (Tetraethyl pyrophosphate) $\mathrm{LD}_{50} 1.12 \mathrm{mg} / \mathrm{kg}$ bw, (Toxicity class Ia); highly toxic (Methamidophos), Mammals-Acute oral $\mathrm{LD}_{50}$ of $30 \mathrm{mg} / \mathrm{kg}$ bw, and toxicity class Ib; Chlorpyrifos moderately toxic (Toxicity class II) has Mammals-Acute oral $\mathrm{LD}_{50}$ of $66 \mathrm{mg} / \mathrm{kg}$ bw; and malathion slightly toxic (Toxicity class III), has MammalsAcute oral $\mathrm{LD}_{50}$ of $1778 \mathrm{mg} / \mathrm{kg}$ bw. The common sense of these compounds are that they organophosphate insecticides, having high water solubility such as

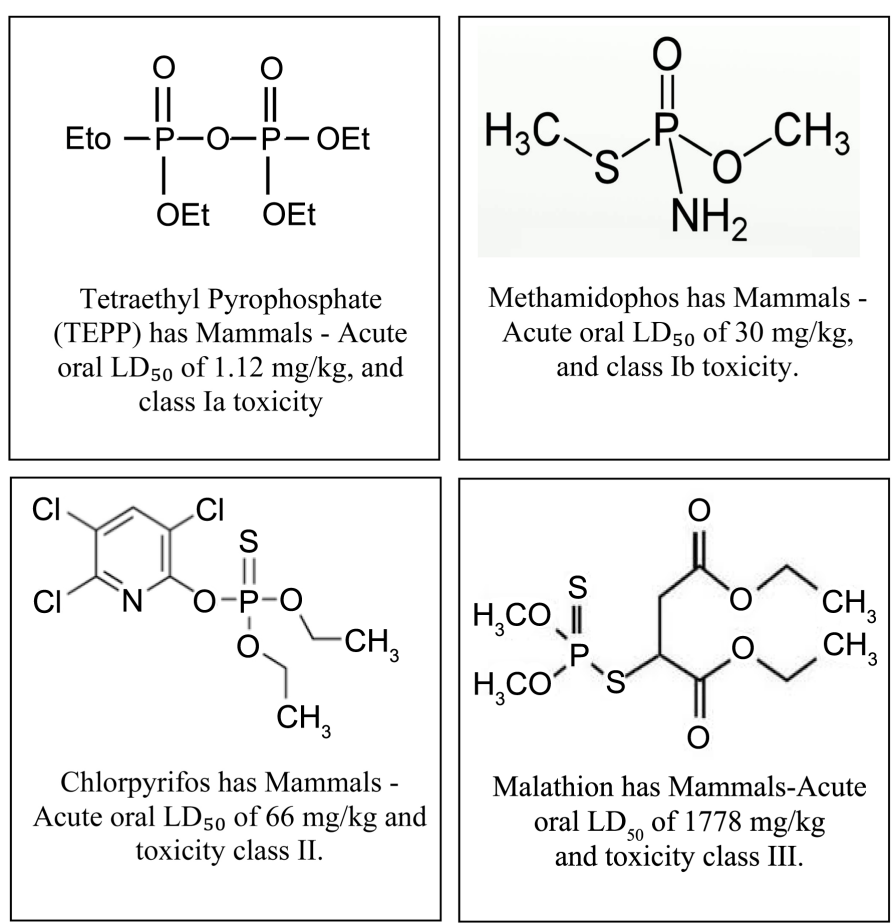

Figure 1. Name, chemical structure, lethal dose $\left(\mathrm{LD}_{50}\right)$, and toxicity class of the poisoning materials. 
Tetraethyl pyrophosphate $(1000,000 \mathrm{mg} / \mathrm{L})$; Methamidophos $(200,000 \mathrm{mg} / \mathrm{L})$; malathion $(148 \mathrm{mg} / \mathrm{L})$; and Chlorpyrifos $(1.05 \mathrm{mg} / \mathrm{L})$. In addition, Log $\mathrm{P}$ values are $2.94,-0.79,4.7$ and 2.75 for Tetraethyl pyrophosphate, Methamidophos, Chlorpyrifos and malathion respectively [23].

As it is clear above, the highest water-solubility insecticides have the lowest $\mathrm{LD}_{50}$ (highest toxicity). The explanation of this argument is that high water solubility may enable fast transfer of the toxic materials through blood stream hence reaching the target sites more rapidly than low water solubility insecticides as for malathion or chlorpyrifos. On the other hand, Log P value has a critical rule in transferring toxic materials through blood barrier.

So far, Table 1(a) shows number of cases involved in the study, age in years, and sex groups of the poisoned cases. Additionally, blood pressure (BP), pulse, temperature, name of poisoning materials, and responses of eye to toxic substances. It can be seen that the presented cases are four female and one male child. Moreover, it appears from BP that all cases have blood pressure lower than the reference range (Table 1(b)). On the other hand, heartbeats are lower than reference range Table 1(b). These data suggest potential cardiotoxicity of the presented cases.

\subsection{Potential Cardiotoxicity of the Cases}

Due to reduced blood pressure and heartbeat, and breath shortness, an electrocardiogram (ECG) of each case was measured and presented in Figure 2. It can be seen that different shapes and magnitudes of cardiograms are produced. These data suggest different type of cardiotoxicity are emerged from the exposure

Table 1. (a) Some toxicity parameters; (b) reference range of heart rate (beat per minute) and blood pressure among different child age.

(a)

\begin{tabular}{cccccccc}
\hline Case \# & $\begin{array}{c}\text { Age } \\
\text { (year) }\end{array}$ & Sex & $\begin{array}{c}\text { Blood } \\
\text { pressure }\end{array}$ & Pulse & $\begin{array}{c}\text { Temp } \\
{ }^{\circ} \mathrm{C}\end{array}$ & Pupil & Poison \\
\hline 1 & 1 & M & $90 / 62$ & $89-93$ & 37 & RRR & Malathion \\
2 & 3 & F & $95 / 65$ & $90-95$ & 37 & RRR & Tetraethyl pyrophosphate \\
3 & 3 & F & $92 / 63$ & $90-92$ & 37 & RRR & chlorpyrifos \\
4 & 2 & F & $90 / 60$ & $85-87$ & 37 & RRR & Scorpion bite \\
5 & 4 & F & $100-105$ & $70 / 40$ & 37 & RRR & Methamidophos \\
\hline
\end{tabular}

(b)

\begin{tabular}{cccc}
\hline \multirow{2}{*}{ Age year } & $\begin{array}{c}\text { Normal heart rate } \\
\text { Ref [24] }\end{array}$ & \multicolumn{2}{c}{ Blood pressure Ref [25] } \\
\cline { 3 - 4 } & 80 to 160 & $87-105$ & Diastolic \\
\hline $1-2.99$ & 80 to 130 & $95-105$ & $53-66$ \\
$3.00-3.99$ & 80 to 120 & $95-110$ & $53-66$ \\
$4.00-5.99$ & 75 to 115 & $97-112$ & $56-70$ \\
\hline
\end{tabular}




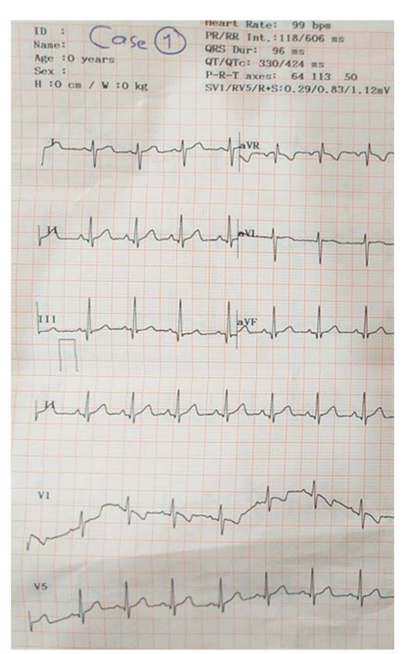

Case \# 1

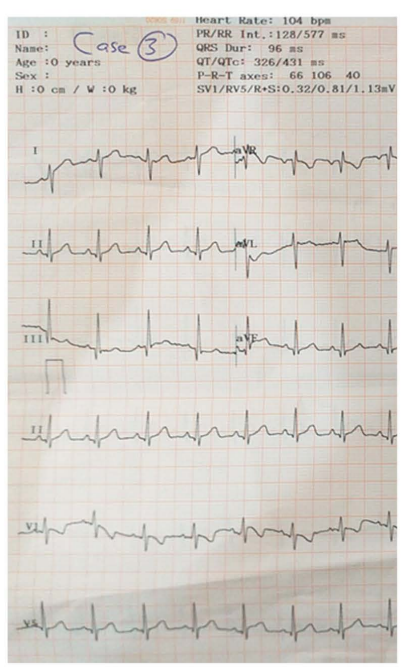

Case \# 3

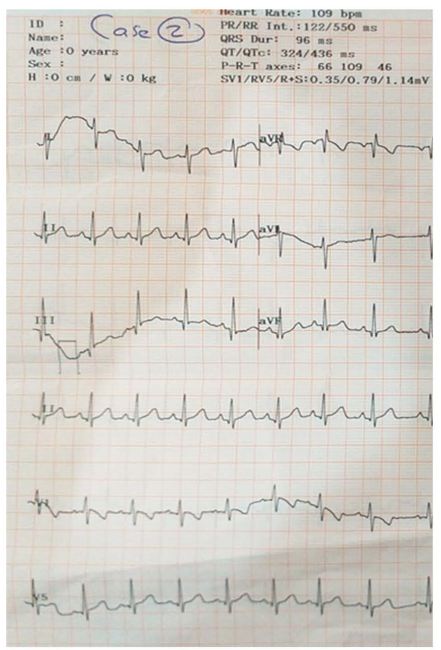

Case \# 2

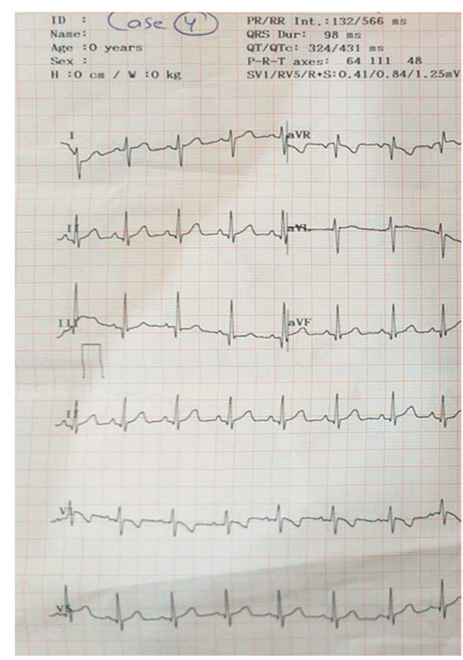

Case \# 4

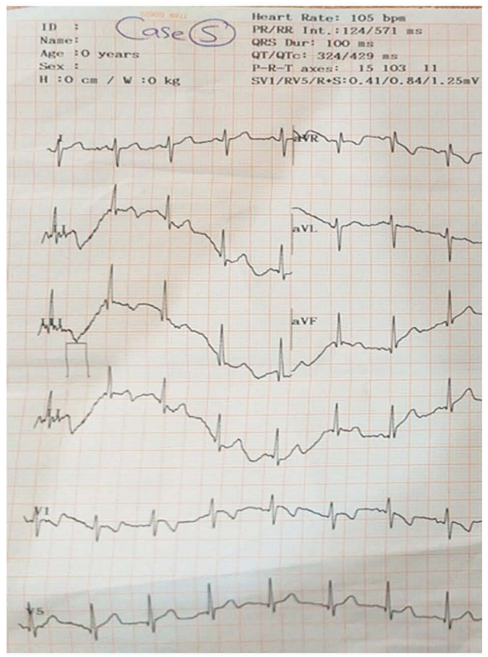

Case \# 5

Figure 2. Electrocardiogram of the each poisoned case. Case \# is shown in each case. The denoted case number in the box is the same number in the table below. 
to toxic materials. The common sense among the cardiograms are they have similar electricity disturbances and similar features of abnormalities, probably due to similar mode of toxicity of the poisoning materials. So far, the following heart complications may be suggested due to poisoning.

\subsubsection{Electrolyte Disturbances and/or Imbalances}

Electrolytes are the ionized salts in blood such as $\left[\mathrm{Na}^{+} \mathrm{Cl}^{-}\right],\left[\mathrm{K}^{+} \mathrm{Cl}^{-}\right]$and $\left[\mathrm{Cl}^{-} \mathrm{Ca}^{+} \mathrm{Cl}^{-}\right]$ which are electricity-conducting particles in the body that help keep the heart muscle beating in rhythm. If electrolytes in the body are imbalanced, and or disturbed, an abnormal ECG reading may happen.

\subsubsection{Heart Attack}

During a heart attack, blood flow in the heart is affected and heart tissue can begin to lose oxygen. This tissue will not conduct electricity as well, which can cause an abnormal ECG.

\subsubsection{Heart Rhythm Abnormalities}

A heart typically beats in a steady rhythm. An ECG can reveal if the heart is beating out of rhythm or sequence. Exposure to pesticides can affect a heart's rate and rhythm and may cause arrhythmias. Electrolyte imbalances, Heart attack, and Ischemic heart.

\subsection{Effect of Poisons on Blood Parameters}

Table 2 shows the blood parameters of the poisoned cases. So far, WBCs exist in the blood, the lymphatic system, and tissues and are an important part of the body's natural defense (immune) system. They act against infections and have a role in inflammation, and allergic reactions. Their numbers are nearly stable in the blood system of a healthy child. However, their count may temporarily shift higher or lower depending on what is going on in the body. For instance, blood disturbance can stimulate bone marrow to produce a higher number of neutrophils to fight against blood disturbance. In general, a bacterial infection, allergies, and poisoning may enhance the formation of WBCs in the blood system

Table 2. Blood parameters of poisoned cases.

\begin{tabular}{ccccccc}
\hline \multirow{2}{*}{ Blood parameters } & \multicolumn{5}{c}{ Case \# } & \multirow{2}{*}{ Ref rate } \\
\cline { 2 - 5 } & $1(\mathrm{M})$ & $2(\mathrm{~F})$ & $3(\mathrm{~F})$ & $4(\mathrm{~F})$ & $5(\mathrm{~F})$ & \\
\hline WBC & 5.9 & 13.1 & 8.9 & 10.0 & 11.2 & $(5-21) \mathrm{k} / \mu \mathrm{l}$ \\
RBC & 3.69 & 4.68 & 4.69 & 4.75 & 4.38 & $(3.9-5.9) \mathrm{m} / \mu \mathrm{l}$ \\
HGB & 9.1 & 11.9 & 12.5 & 12.2 & 11.8 & $(11.5-15.5) \mathrm{g} / \mathrm{dL}$ \\
HCT & 27.8 & 34.8 & 37.3 & 36.7 & 36.4 & $(31-66) \%$ \\
MCH & 24.7 & 25.4 & 26.7 & 25.7 & 26.9 & $(24-37) \mathrm{pg}$ \\
MCHC & 32.7 & 34.2 & 33.5 & 33.2 & 32.4 & $(30-37) \mathrm{g} / \mathrm{dL}$ \\
PLT & 251 & 244 & 215 & 310 & 198 & $(150-450) \mathrm{k} / \mu \mathrm{l}$ \\
\hline
\end{tabular}


and increased number above the lower limit. So far, the WBCs number may go back to the normal range if the causing factors disappear. For our poisoning cases, it appears that WBCs counts increased with different ranges above the lower limit in all cases, but they are still lower than the upper limit (Table 2). The lowest increase was with malathion poisoning (case 1) whereas the highest increase was with Methamidophos poisoning (case 5). Scorpion bit (poisoning case 4) showed elevated levels of WBCs count. In the above-mentioned poisoning cases blood responded to poisoning through antibody-antigen reaction. This explanation is in accordance with Jiang et al., [26], and Cifuentes [27] who reported antibody-antigen reactions with other cases.

Additionally, red blood cells (RBCs), also called erythrocytes, are produced in the bone marrow and released into the bloodstream when they mature. They contain hemoglobin, a protein that transports oxygen throughout the body. So far, a number of factors and conditions can affect the production of new RBCs and/or their lifespan, in addition to those conditions that may result in significant bleeding. For instance (Table 2), RBCs are increased above the lower limit of most cases except case 1. This increase may due to the reason of poisoning cases.

Furthermore, platelets (PLT), also called thrombocytes, are actually tiny cell fragments that circulate in blood and are essential for normal blood clotting. When there is an injury and bleeding begins, platelets help stop bleeding by adhering to the injury site and clumping together to form a temporary plug. They also release chemical signals that attract and promote clumping of additional platelets and eventually become part of a stable blood clot at the site of the injury that remains in place until the injury heals.

If there is a poisoning a disease or condition that causes low platelets (thrombocytopenia) or dysfunction of platelets. This condition may increase risk of excessive bleeding. On the other hand at an excess of platelets (thrombocytosis), a possible blood clotting may occur. If this happens in the heart muscles, myocardial infarction may occur resulting in cardiotoxicity. For the cases in Table 2, platelets counts were increased above the lower limit of the reference range suggesting the involvement of PLT in toxicity/de-toxicity reactions.

In general, the increases of blood parameters above the lower limit indicate the interaction of blood system toxicity/de-toxicity reactions. If the increase exceed the upper limit of blood parameters this indicate sever blood poisoning.

\subsection{Effect of Poisons on Blood Electrolytes}

Table 3 shows the changes of electrolytes, sodium, potassium and chloride ions, $\left(\mathrm{Na}^{+}, \mathrm{K}^{+}, \mathrm{Ca}^{2+}\right)$ concentration in poisoning cases. So far, sodium $\left(\mathrm{Na}^{+}\right)$is the major positive ion (cation) in fluid outside of cells. When combined with chloride ion $\left(\mathrm{Cl}^{-}\right)$, the resulting substance is table salt $\mathrm{NaCl}$. Sodium regulates the total amount of water in the body and the transmission of sodium into and out of individual cells also plays a role in critical body functions. Many processes in 
Table 3. Sodium, potassium calcium and other parameters of poisoned cases.

\begin{tabular}{ccccccc}
\hline \multirow{2}{*}{ Ion name } & \multicolumn{5}{c}{ Case \# } & \multirow{2}{*}{ Ref rate } \\
\cline { 2 - 5 } & $1(\mathrm{M})$ & $2(\mathrm{~F})$ & $3(\mathrm{~F})$ & $4(\mathrm{~F})$ & $5(\mathrm{~F})$ & \\
\hline $\mathrm{Na}^{+}$ & 141 & 143 & 143 & nd & 144 & $(135-145) \mathrm{mmol} / \mathrm{L}$ \\
$\mathrm{K}^{+}$ & 5.5 & 4.4 & 6.0 & nd & 2.8 & $(3.6-5.1) \mathrm{mmol} / \mathrm{L}$ \\
$\mathrm{Ca}^{2+}$ & 9.6 & 11.6 & 8.8 & nd & 10.04 & $(8.4-10.2) \mathrm{mmol} / \mathrm{L}$ \\
\hline
\end{tabular}

the body, especially in the brain, nervous system, and muscles, require electrical signals for communication. The movement of sodium is critical in the generation of these electrical signals. So far excess of $\mathrm{Na}^{+}$ion concentration (hypernatremia) or a decrease concentration (hyponatremia) may occur due to different disturbances resulting in a disturbance of polarization and depolarization potential of the nerve system supporting the heart, leading to cardiotoxicity. For the poisoning cases in Table 3. It appeared that $\mathrm{Na}^{+}$ion increased above the lower limit suggesting a nerve disturbance due to poisoning case. $\mathrm{Na}^{+}$ion increase was more pronounced in case five than all cases suggesting a sever effects of poison. On the other hand, potassium $\left(\mathrm{K}^{+}\right)$is the major positive ion (cation) found inside of cells. A seriously abnormal increase in potassium (hyperkalemia) or decrease in potassium (hypokalemia) can profoundly affect the nervous system and increases the chance of irregular heartbeats (arrhythmias), which, when extreme, can be fatal. Additionally, Ca-ion showed similar response to poisoning (Table 3).

In general, concentration of electrolytes are above the lower limit or the reference range (Table 3 ), except $\mathrm{K}$ ion in case 5 is below the lower limit of the reference range. These data indicate the disturbance and imbalance of the electrolyte concentration. This is in accordance with the disturbances in the electrocardiogram (Figure 2).

\subsection{Effect of Poisons Urea, Creatinine and Glucose}

Moreover, Table 4 shows the changes in urea, creatinine, glucose concentrations and the activities of AChE, ALT, AST and ALP.

It is obvious that urea concentration increased above the lower limit in poisoning cases 1, 3 and 4; and increased above the higher limit in poisoning cases 2 and 5. In fact, urea is a nitrogen-metabolic waste product that forms during the metabolism of protein. It is released by liver into the blood and being filtered out of the blood and eliminated in the urine by the kidney. Accordingly, urea level in blood serum is bioindicator of healthy kidney. High urea levels in blood serum (above range) suggest that kidneys are not working well. This may occur due to cardiotoxicity, heart failure. Similarly, creatinine is another waste product that is produced by the body's muscles and is eliminated by the kidneys.

High creatinine level in blood serum (above range) suggest some failure of kidney function. This may occur in response to exposure to pesticides [10] and/or cardiotoxicity and heart failure (Figure 2). So far, creatinine level in 
Table 4. Activities of urea, creatinine, glucose, AChE, ALT, AST and ALP profile of poisoned cases.

\begin{tabular}{ccccccc}
\hline \multirow{2}{*}{ Enzyme } & \multicolumn{5}{c}{ Case \# } & \multirow{2}{*}{ Ref range } \\
\cline { 2 - 5 } & $1(\mathrm{M})$ & $2(\mathrm{~F})$ & $3(\mathrm{~F})$ & $4(\mathrm{~F})$ & $5(\mathrm{~F})$ & \\
\hline Urea & 16 & 31 & 20 & 28 & 31 & $(5-30) \mathrm{mg} / \mathrm{dl}$ \\
Creatinine & 0.5 & 0.6 & 0.48 & 0.47 & 0.8 & $(0.3-0.7) \mathrm{mg} / \mathrm{dl}$ \\
Glucose & 118 & 170 & 103 & 82 & 334 & $(80-120) \mathrm{mg} / \mathrm{dl}$ \\
AChE & 7210 & 3869 & 4583 & 8569 & 390 & $(5000-8000)$ \\
ALT & nd & nd & 21 & 26 & 15 & $0-43$ \\
AST & nd & nd & 23 & 41 & 43 & $0-31$ \\
ALP & nd & nd & 644 & 703 & 719 & $50-250$ \\
\hline
\end{tabular}

blood serum is above the lower limit in most case and above higher limit in case 5. This suggests sever effect in case 5 .

Furthermore, glucose level in blood serum jumped to be close the upper limit in poisoning case 1 (malathion poisoning), exceeded the upper limit in case 2 (poisoning with Tetraethyl pyrophosphate), above the lower limit in chlorpyrifos poisoning (case 3), close to the lower limit in scorpion bit (case 4) and several times higher than upper limit of reference range in case 5 (Methamidophos poisoning).

The explanation of these results is that exposure to OP insecticides such as those presented in Figure 1 may disturb the metabolic pathways of food resulting in an increase of glucose level in blood. This explanation is in agreement with previous reports [28] [29] that revealed significant glucose level changes due to exposure to OP insecticides. Additionally, metabolic diseases, biochemical, metabolic alterations [30]. Furthermore, chlorpyrifos has a high log $\mathrm{P}$ value (Figure 1), this enable lipid solubility and possible deposit in the liver [31]. Liver has an essential role in blood-glucose modulation such as glycogenesis, glycogenolysis, and gluconeogenesis [32]. So far chlorpyrifos may disrupts glucose modulation leading to hyperglycemia or hypoglycemia, based on the time and dose of exposure. Previous results showed increased level of blood glucose (3.3-fold) higher in malathion exposed rats than in the control group indicating alteration of glucose homeostasis due to toxicity [33]. In contrast, Farkhondeh et al. [34] found that exposure with organophosphate pesticides may suppress excessive blood glucose levels with no effect on the basal blood glucose in the fasting adult male mice.

Furthermore, Table 4 shows a slight reduction in AChE activity in poisoning with malathion (poisoning case 1) and sever reduction in poisoning with $\mathrm{Te}$ traethyl pyrophosphate, and chlorpyrifos, poisoning cases 2 and 3 respectively. Additionally, an extreme reduction in AChE activity was observed Methamidophos (poisoning case 5). In contrast a slight increase in AChE activity in poisoning case with scorpion bit (poisoning case 4). This indicates that scorpion 
venom has no effect on $\mathrm{AChE}$ activity. On the other hand, scorpion venom caused blood disturbance through antigen antibody reaction as shown by WBC elevation in case 4 (Table 2). On the other hand, changes in ALT activity in all case did not exceed the upper range. Meanwhile, tremendous increases in the activities of AST, and ALP were observed in poisoning cases 3 - 5. The activity of each enzyme increase above the higher limit suggesting potential liver damage.

It is well know in the literature that $\mathrm{OP}$ insecticides are strong inhibitors to AChE. This is in accordance with the explanation given above.

\subsection{Clinical Aspects of Poisons}

Furthermore, clinical symptoms associated with poisoning cases are shown in Table 5.

Table 5 shows the following clinical symptoms, (anorexia, diarrhea, headache, nausea, vomiting, weakness) appeared in poisoning case 1 and 2 .

The explanation of these symptoms is that at a certain inhibition to AChE, acetylcholine base tends to accumulation in the synaptic gaps. Under this condition,

Table 5. Clinical symptoms of poisoned cases.

\begin{tabular}{|c|c|c|c|c|c|c|}
\hline \multirow{2}{*}{ Clinical symptoms } & \multicolumn{5}{|c|}{ Case \# } & \multirow{2}{*}{ Ref range } \\
\hline & $1(\mathrm{M})$ & $2(\mathrm{~F})$ & $3(\mathrm{~F})$ & $4(\mathrm{~F})$ & $5(\mathrm{~F})$ & \\
\hline Anorexia & - & $\sqrt{ }$ & - & - & - & 0 \\
\hline Diarrhea & $\sqrt{ }$ & $\sqrt{ }$ & - & - & - & 0 \\
\hline Headache & $\sqrt{ }$ & - & - & - & - & 0 \\
\hline Nausea & - & $\sqrt{ }$ & - & - & - & 0 \\
\hline Weakness & $\sqrt{ }$ & - & - & - & - & 0 \\
\hline Vomiting & $\sqrt{ }$ & $\sqrt{ }$ & - & - & - & 0 \\
\hline Pain & - & - & - & $\sqrt{ }$ & - & 0 \\
\hline Tingling & - & - & - & $\sqrt{ }$ & - & 0 \\
\hline Sensation & - & - & - & $\sqrt{ }$ & - & 0 \\
\hline Blurry vision & - & - & - & $\sqrt{ }$ & - & 0 \\
\hline Convulsion & - & - & - & $\sqrt{ }$ & - & 0 \\
\hline Unconsciousness & - & - & - & $\sqrt{ }$ & - & 0 \\
\hline Very narrowed pupils & - & - & - & - & $\sqrt{ }$ & 0 \\
\hline Confusion & - & - & - & - & $\sqrt{ }$ & 0 \\
\hline Body sectarian & - & - & - & - & $\sqrt{ }$ & 0 \\
\hline Sweeting & - & - & - & - & $\sqrt{ }$ & 0 \\
\hline Saliva & - & - & - & - & $\sqrt{ }$ & 0 \\
\hline Mucous & - & - & - & - & $\sqrt{ }$ & 0 \\
\hline Tears & - & - & - & - & $\sqrt{ }$ & 0 \\
\hline Irregular heart beat & - & - & - & - & $\sqrt{ }$ & 0 \\
\hline Respiratory depression & - & - & - & - & $\sqrt{ }$ & 0 \\
\hline
\end{tabular}


the muscles may stop responding to the high synaptic levels of $\mathrm{ACh}$, leading to flaccid paralysis (a neurological condition characterized by weakness, paralysis, or reduced muscle tone), respiratory failure, and other symptoms such as mentioned above. At this case, the stimulation occurred on the nicotinic receptors. On the other hand at sever poisoning; large fraction of acetylcholine base is accumulated in the synaptic gaps resulting in over stimulation in the cholinergic and muscarinic receptors. At this case symptoms similar to that in poisoning case 3 and 5 may appear.

Moreover, appearance of symptoms such as increased sweating, salivation, bronchial secretions are in accordance with the ECG (Figure 2).

Additionally, increased cholinergic stimulation include: salivation, lacrimation, urination, defecation, gastrointestinal distress, vomiting, miosis, and muscle spam. It can be suggested that a low accumulation of acetylcholine in the synaptic gap cholinergic symptoms may appear as those in poisoning cases 1 and 2 whereas at high accumulation of acetylcholine in the synaptic gap muscarinic symptoms may appear such as those in poisoning case 3 and 5 . These symptoms are in accordance with the inhibition levels of AChE (Table 4)

\subsection{Heart Complication among Exposed Population}

Heart complication or cardiotoxicity may occur due to acute organophosphate poisoning which cause arrhythmias, hyper pressure [35] and created low blood pressure in dimethoate poisoned cases [36]. Organophosphate (OP) insecticide poisoning created tachycardia, ventricular fibrillation, and bradycardia among poisoned children [37]. Recently, El-Nahhal and El-Nahhal [6] discussed in details the cardiotoxicity among population caused by different pesticides and also provided alternative nutritional to pesticide antidote.

\subsection{Mechanisms of Cardiotoxicity}

In acute or chronic organophosphate poisoning cases, the OP insecticide inhibits acetylcholinesterase in the nervous system supporting the heart. The degree of inhibition depends on the chemical structure of OP insecticide, its solubility in blood and Log P value as elaborated above. This may result in convulsions, tremors, and paralysis creating cardia disorders. In acute poisoning accumulation of acetylcholine may take place in synaptic gaps in the heart-supporting nervous system, causing cardiac disorders [38]. This may lead to a muscarinic syndrome characterized by miosis in the eyes, profuse secretions, bradycardia, bronchoconstriction (tightness in the chest and wheezing) as shown for the poisoning cases mentioned above, in accordance with previous reports [39]. However, cardiac problems in cases of organophosphate poisoning were observed with malathion [40], and chlorpyrifos [41] [42] [43] [44].

Modeling the Heart Toxicity

Equation (1) describes the potential mechanism of cardiotoxicity, 


$$
[\mathrm{t}-\mathrm{AChE}]=[\mathrm{f}-\mathrm{AChE}]+[\mathrm{b}-\mathrm{AChE}]
$$

where, [t-AChE], [f-AChE], [b-AChE], are the concentration of total, free and bound form of acetylcholinesterase in human body, respectively.

At normal condition [f-AChE] is higher than bound form, accordingly [b$\mathrm{AChE}$ ] is extremely low as in Equation (2).

$$
\frac{[\text { f-AChE }]}{[\text { b-AChE }]}>1
$$

Thus, we have a range of enzyme activity.

At a certain level of cardiotoxicity, the concentration of the $\mathrm{f}-\mathrm{AChE}$ tend to decrease and concentration to decrease of b-AChE tend to increase to a certain point. This is the starting point of appearance of clinical symptoms of toxicity.

Progressively, the free form of enzyme becomes equal to the bound form as in Equation (3) at which point, the toxic symptoms tend to increase.

$$
\frac{[\mathrm{f}-\mathrm{AChE}]}{[\mathrm{b}-\mathrm{AChE}]}=1
$$

At a late stage of toxicity, if the case continues without medical interference the free enzyme form becomes less than bound form and under this condition, cardiotoxicity become severe and the patient may become unconscious as in Equation (4).

$$
\frac{[\mathrm{f}-\mathrm{AChE}]}{[\mathrm{b}-\mathrm{AChE}]}<1
$$

If Equation (4) continues for a long time, the patient may be dead or severe damage may occur to the heart.

\subsection{Advantages and Disadvantages of Using Anti-Poisoning Medical Drugs}

It has been shown that using atropine; obidoxime (standard medical treatments for poisoning) [45] [46] [47], and benzodiazepines as neuroprotectants and anticonvulsants [48] successfully recovered the poisoning in few cases of OP poisoning and many cases of carbamate-poisoning. In contrast, the use of a muscarinic antagonist, e.g., atropine has been associated with an increased prevalence of myopia among populations using atropine [49], photophobia and slowing eye growth and visual side effects [50]. Injection of obidoxime caused many disadvantages (e.g., nausea, pyrosis, headache, weakness, and sore throat) [51].

\subsection{Alternatives of Medical Treatment for Cardiotoxicity}

Here below, we provided naturally occurring material (vitamin C, vitamin E, curcumin, quercetin, selenium, chrysin, and garlic extract) as suitable dietary materials to replace the use atropine; an oxime, mostly pralidoxime or obidoxime for curing poisoning cases.

It has been shown that melatonin chrysin. And $\mathrm{N}$-acetyl cysteine] treatments 
were successful in curing oxidative stress biomarkers induced by AlP in cardiac tissues.

Ginger and zinc chloride cured histopathological damage in the liver and kidney induced by malathion toxicity in rats [6] [52]. Noteworthy, Ziziphora extract (an antioxidant), cured oxidative stress caused by chlorpyrifos in lung tissue in rat [53]. Similarly, Propolis cured hyperglycemia caused by chlorpyrifos [54]. Vitamin C reduced the levels of superoxide dismutase, glutathione-S-transferase, in cardiac tissues induced by diazinon in male Wistar rats similar observation was reported with vitamins $\mathrm{E}$ and $\mathrm{C}$ in combination.in rats [55]. Additionally, gavage of ginger juice and garlic extract activated neuro-enzymes and curing the tissue damage induced by dichlorvos in Wistar rats [56].

\subsection{Mechanism of Poisoning Recovery by the Use of Alternatives}

Mechanisms of cardiotoxicity recovery is described below.

Hear complication (cardiotoxicity) caused by pesticides may be described by Equation (5), where OPi and AChE represent free organophosphate insecticide and free enzyme, respectively. At a certain level of organophosphate insecticide exposure, free enzyme $\mathrm{E}$ becomes bound to free pesticide $(\mathrm{OPi})$, forming a pesticide-enzyme complex that later results in cardiotoxic symptoms, as demonstrated above.

$$
\mathrm{OPi}+\mathrm{AChE} \rightarrow[\mathrm{OPAChEi}]
$$

The use of alternative agent (A) may release of the bound enzyme from the complex, Equation (6) resulting in a recovery of poisoning

$$
[\mathrm{OPAChEi}]+\mathrm{A} \rightarrow[\mathrm{OPiA}]+\mathrm{AChE}
$$

However, an alternative agent that can provide protection to the active enzyme.

Equation (7) shows the potential ability of the alternative agent to directly react with the pesticide molecule, forming a complex (OPiA) that does not allow the pesticide molecule to react with active sites in the cardiovascular system, resulting in heart protection.

$$
\mathrm{OPi}+\mathrm{AChE}+\mathrm{A} \rightarrow[\mathrm{OPiA}]+\mathrm{AChE}
$$

These mechanisms are in accordance with recent report Ref [6].

\section{Conclusions}

This report highlights the cardiotoxicity among children and shows the electrocardiogram changes, hematological changes, and biochemical changes due to poisoning. The report shows the toxicity groups and chemical class of poisons among children. The poisons were organophosphate insecticide from toxicity classes Ia, Ib, II, and III.

The report provides some alternative agents to medical drugs that successfully managed some cases elsewhere. Vitamin C, vitamin E, curcumin, quercetin, selenium, chrysin, and garlic extract showed great ability to cure poisoning. 
In conclusion, this report provides scientific evidence of cardiotoxic pesticides among children and potential alternative medical agents for cardiotoxicity.

\section{Acknowledgements}

Prof Dr. Yasser El-Nahhal thanks the AvH foundation for funding a research stay in Berlin, Germany.

\section{Conflicts of Interest}

The authors declare no conflicts of interest regarding the publication of this paper.

\section{References}

[1] El-Nahhal, Y., Nir, S., Polubesova, T., Margulies, L. and Rubin B. (1997) Organo-Clay Formulations of Alachlor: Reduced Leaching and Improved Efficacy. Proceedings of Brighton Crop Protection Conference Weeds, 1, 21-26.

[2] El-Nahhal, Y. (2003) Adsorptive Behavior of Acetochlor on Organoclay Complexes. Bulletin of Environmental Contamination and Toxicology, 70, 1104-1111. https://doi.org/10.1007/s00128-003-0096-Z

[3] El-Nahhal, Y., Lagaly, G. and Rabinovitz, O. (2005) Organoclay Formulations of Acetochlor: Effect of High Salt Concentration. Journal of Agricultural and Food Chemistry, 53, 1620-1624. https://doi.org/10.1021/jf040383a

[4] EL-Nahhal, Y. and Alshanti, A. (2015) Toxicity of Single and Mixtures Antibiotics to Cyanobacteria. Environment and Analytical Toxicology, 5, Article No. 274.

[5] Schecter, A., Papke, O., Isaac, J., Hrimat, N., Neiroukh, F., Safi, J. and El-Nahhal, Y. (1997) 2,3,7,8 Chlorine Substituted Dioxins and Dibenzofuran Congeners in 2,4-D, 2,4,5-T and Pentachlorophenol. Organohalogen Compounds, 32, 51-55.

[6] El-Nahhal, Y. and El-Nahhal, I. (2021) Cardiotoxicity of Some Pesticides and Their Amelioration. Environmental Science and Pollution Research, 28, 44726-44754. https://doi.org/10.1007/s11356-021-14999-9

[7] El-Nahhal, Y. (2020) Pesticide Residues in Honey and Their Potential Reproductive Toxicity. Science of the Total Environment, 741, Article ID: 139953. https://doi.org/10.1016/j.scitotenv.2020.139953

[8] El-Nahhal, I. and El-Nahhal, Y. (2021) Pesticide Residues in Drinking Water, Their Potential Risk to Human Health and Removal Options. Journal of Environmental Management, 299, Article ID: 113611. https://doi.org/10.1016/j.jenvman.2021.113611

[9] El-Nahhal, Y. (2014) Development of Controlled Release Formulations of Thiabendazole. Journal of Agricultural Chemistry and Environment, 3, 1-8. https://doi.org/10.4236/jacen.2014.31001

[10] Nahhal, Y. (2016) Biochemical Changes Associated with Long Term Exposure to Pesticide among Farmers in the Gaza Strip. Occupational Diseases and Environmental Medicine, 4, 72-82. https://doi.org/10.4236/odem.2016.43009

[11] El-Nahhal, Y.Z. and Safi, J.M. (2004) Adsorption of Phenanthrene on Organoclays from Distilled and Saline Water. Journal of Colloid and Interface Science, 269, 265-273. https://doi.org/10.1016/S0021-9797(03)00607-6

[12] Safi, J.M., Yassin, M.M., El-Nahhal, Y.Z., Abed, Y.A., Safi, M.J. and Suleiman, H.D. (2019) Childhood Lead Poisoning in Gaza Strip, the Palestinian Authority. Journal 
of Trace Elements in Medicine and Biology, 54, 118-125. https://doi.org/10.1016/j.jtemb.2019.04.004

[13] El-Nahhal, Y. and Safi, J. (2004) Stability of an Organo Clay Complex: Effects of High Concentrations of Sodium Chloride. Applied Clay Science, 24, 129-136. https://doi.org/10.1016/j.clay.2003.01.002

[14] El-Nahhal, Y. and Radwan, A. (2013) Human Health Risks: Impact of Pesticide Application. Journal of Environment and Earth Science, 3, 199-209.

[15] El-Nahhal, Y. and Safi, J. (2005) Adsorption of Benzene and Naphthalene to Modified Montmorillonite. Journal of Food, Agriculture and Environment, 3, 295-298.

[16] EL-Nahhal, Y., EL-Najjar, Sh. and Afifi, S. (2015) Impact of Organic Contamination on Some Aquatic Organisms. Toxicology International, 22, 45-53.

[17] El-Nahhal, Y., Wheidi, B. and El-Kurdi, S. (2016) Development of Ecologically Acceptable Chlorpyrifos Formulation for Effective and Safe Application. Journal of Encapsulation and Adsorption Sciences, 6, 91-108.

https://doi.org/10.4236/jeas.2016.63008

[18] El-Nahhal, Y. (2003) Adsorption Mechanism of Chloroacetanilide Herbicides to Modified Montmorillonite. Journal of Environmental Science and Health: Part. B, Pesticides, Food Contaminants, and Agricultural Wastes, 38, 591-604. https://doi.org/10.1081/PFC-120023517

[19] EL-Nahhal, I. and El-Nahhal, Y. (2020). Hyperlink “javascript:void(0)” Ecological Consequences of COVID-19 Outbreak. Journal of Water Science and Engineering, $1,1-5$.

[20] Ellman, G.L., Courtney, K.D., Andres Jr., V. and Feather-Stone, R.M. (1961) A New and Rapid Colorimetric Determination of Acetylcholinesterase Activity. Biochemical Pharmacology, 7, 88-95. https://doi.org/10.1016/0006-2952(61)90145-9

[21] Bessey, O.A., Lowry, O.H. and Brock, M.J. (1946) A Method for the Rapid Determination of Alkaline Phosphates with Five Cubic Millimeters of Serum. The Journal of Biological Chemistry, 164, 321-329. https://doi.org/10.1016/S0021-9258(18)43072-4

[22] Yan, G.M., Dai, M. and Xuan, Z.H. (2015) Therapeutic Effect of Paconol on Alcoholic Fatty Liver in Rats. Journal of Chinese Medicinal Materials, 38, 550-555.

[23] Pesticides Properties Data Base (2007) A to Z Index-University of Hertfordshire. Last Updated: 01/08/2020.https://sitem.herts.ac.uk/aeru/ppdb/en/atoz.htm

[24] NIH (National Institutes of Health) (2021) What Should My Heart Rate Be? https://www.medicalnewstoday.com/articles/235710\#normal-resting-heart-rate

[25] University of Iowa Stead Family Children's Hospital (2021) Vital Signs: Normal Blood Pressure (mmHg) (PICU Chart).

https://uichildrens.org/health-library/vital-signs-normal-blood-pressure-mmhg-pic u-chart

[26] Jiang, J.Y., Zhang, L., Qin, L., Luo, J.Y., Fu, Y.W., Qin, J.A., Wang, C.J., Ouyang, Z. and Yang, M.H. (2020) Zhongguo Zhong Yao Za Zhi = Zhongguo Zhongyao Zazhi = China Journal of Chinese Materia Medica, 45, 3900-3907. (In Chinese) https://doi.org/10.19540/j.cnki.cjcmm.20200522.201

[27] Cifuentes, L. (2015) Allergy to Honeybee ... Not Only Stings. Current Opinion in Allergy and Clinical Immunology, 15, 364-368.

https://doi.org/10.1097/ACI.0000000000000191

[28] Pournourmohammadi, S., Farzami, B., Ostad, S.N., Azizi, E. and Abdollahi, M. (2005) Effects of Malathion Subchronic Exposure on Rat Skeletal Muscle Glucose 
Metabolism. Environ Toxicol Pharmacol, 19, 191-196. https://doi.org/10.1016/j.etap.2004.07.002

[29] Farkhondeh, T., Amirabadizadeh, A., Samarghandian, S. and Mehrpour, O. (2020) Impact of Chlorpyrifos on Blood Glucose Concentration in an Animal Model: A Systematic Review and Meta-Analysis. Environmental Science and Pollution Research International, 27, 2474-2481. https://doi.org/10.1007/s11356-019-07229-w

[30] Zepeda-Arce, R., Rojas-García, A.E., Benitez-Trinidad, A., Herrera-Moreno, J.F., Medina-Díaz, I.M., Barrón-Vivanco, B.S., Villegas, G.P., Hernández-Ochoa, I., Sólis Heredia, M.J. and Bernal-Hernández, Y.Y. (2017) Oxidative Stress and Genetic Damage among Workers Exposed Primarily to Organophosphate and Pyrethroid Pesticides. Environmental Toxicology, 32, 1754-1764.

https://doi.org/10.1002/tox.22398

[31] Tanvir, E.M., Afroz, R., Chowdhury, M., Gan, S.H., Karim, N., Islam, M.N. and Khalil, M.I. (2016) A Model of Chlorpyrifos Distribution and Its Biochemical Effects on the Liver and Kidneys of Rats. Human \& Experimental Toxicology, 35, 991-1004. https://doi.org/10.1177\%2F0960327115614384

[32] El-Nahhal, Y., EL-dahdouh, N., Hamdona, N. and Alshanti, A. (2016). Toxicological Data of Some Antibiotics and Pesticides to Fish, Mosquitoes, Cyanobacterial Mats and to Plants. Data in Brief, 6, 871-880.

https://doi.org/10.1016/j.dib.2016.01.051

[33] Ramirez-Vargas, M.A., Flores-Alfaro, E., Uriostegui-Acosta, M., Alvarez-Fitz, P., Parra-Rojas, I. and Moreno-Godinez, M.E. (2018) Effects of Exposure to Malathion on Blood Glucose Concentration: A Meta-Analysis. Environmental Science and Pollution Research International, 25, 3233-3242. https://doi.org/10.1007/s11356-017-0890-5

[34] Farkhondeh, T., Aschner, M., Sadeghi, M., Mehrpour, O., Naseri, K., Amirabadizadeh, A., Roshanravan, B., Aramjoo, H. and Samarghandian, S. (2021) The effect of Diazinon on Blood Glucose Homeostasis: A Systematic and Meta-Analysis Study. Environmental Science and Pollution Research International, 28, 4007-4018. https://doi.org/10.1007/s11356-020-11364-0

[35] Bar-Meir, E., Schein, O., Eisenkraft, A., Rubinshtein, R., Grubstein, A., Militianu, A. and Glikson, M. (2007) Guidelines for Treating cardiac Manifestations of Organophosphates Poisoning with Special Emphasis on Long QT and Torsades De Pointes. Critical Reviews in Toxicology, 37, 279-285. https://doi.org/10.1080/10408440601177855

[36] Eddleston, M., Eyer, P., Worek, F., Mohamed, F., Senarathna, L., von Meyer, L., Juszczak, E., Hittarage, A., Azhar, S., Dissanayake, W., Sheriff, M.H., Szinicz, L., Dawson, A.H. and Buckley, N.A. (2005) Differences between Organophosphorus Insecticides in Human Self-Poisoning: A Prospective Cohort Study. Lancet, 366, 1452-1459. https://doi.org/10.1016/S0140-6736(05)67598-8

[37] Liang, Y., Tong, F., Huang, F., Liu, Y., Zhu, L., Le Grange, J.M., He, G. and Zhou, Y. (2020) Pathological Changes Induced by Phosphine Poisoning: A Study on 8 Children. International Journal of Legal Medicine, 134, 217-228. https://doi.org/10.1007/s00414-019-02169-z

[38] Pereira, E.F., Aracava, Y., DeTolla Jr., L.J., Beecham, E.J., Basinger Jr., G.W., Wakayama, E.J. and Albuquerque, E.X. (2014) Animal Models That Best Reproduce the Clinical Manifestations of Human Intoxication with Organophosphorus Compounds. The Journal of Pharmacology and Experimental Therapeutics, 350, 313-321. https://doi.org/10.1124/jpet.114.214932

[39] Hurst, C.G., Newmark, J. and Romano Jr., J.A. (2012) Chemical Terrorism: Introduc- 
tion. In: Longo, D.L., Fauci, A.S., Kasper, D.L., Hauser, S.L., Jameson, J.L. and Loscalzo, J., Eds., Harrison's Principles of Internal Medicine, 18th Edition, McGraw-Hill, New York, 1779-1788.

[40] Zago, A.M., Faria, N., Fávero, J.L., Meucci, R.D., Woskie, S. and Fassa, A.G. (2020) Pesticide Exposure and Risk of Cardiovascular Disease: A Systematic Review. Global Public Health, 1-23. https://doi.org/10.1080/17441692.2020.1808693

[41] El-Nahhal, Y., Lubbad, R. and Al-Agha, M.R. (2020) Toxicity Evaluation of Chlorpyrifos and Diuron Below Maximum Residue Limits in Rabbits. Toxicology and Environmental Health Sciences, 12, 177-190. https://doi.org/10.1007/s13530-020-00015-Z

[42] El-Nahhal, Y. and Lubbad, R. (2018) Acute and Single Repeated Dose Effects of Low Concentrations of Chlorpyrifos, Diuron, and Their Combination on Chicken. Environmental Science and Pollution Research International, 25, 10837-10847. https://doi.org/10.1007/s11356-018-1313-y

[43] El-Nahhal, Y. (2017) Acute Poisoning among Farmers by Chlorpyrifos: Case Report from Gaza Strip. Occupational Diseases and Environmental Medicine, 5, 47-57. https://doi.org/10.4236/odem.2017.52005

[44] El-Nahhal, Y. (2017) Risk Factors among Greenhouse Farmers in Gaza Strip. Occupational Diseases and Environmental Medicine, 5, 1-10. https://doi.org/10.4236/odem.2017.51001

[45] Newmark, J. (2004) Therapy for Nerve Agent Poisoning. Archives of Neurology, 61, 649-652. https://doi.org/10.1001/archneur.61.5.649

[46] Eddleston, M., Buckley, N.A., Eyer, P. and Dawson, A.H. (2008) Management of Acute Organophosphorus Pesticide Poisoning. Lancet, 371, 597-607. https://doi.org/10.1016/S0140-6736(07)61202-1

[47] Pawar, K.S., Bhoite, R.R., Pillay, C.P., Chavan, S.C., Malshikare, D.S. and Garad, S.G. (2006) Continuous Pralidoxime Infusion versus Repeated Bolus Injection to Treat Organophosphorus Pesticide Poisoning: A Randomised Controlled Trial. Lancet, 368, 2136-2141. https://doi.org/10.1016/S0140-6736(06)69862-0

[48] Marrs, T.C. and Sellström, A (2007) The Use of Benzodiazepines in Organophosphorus Nerve Agent Intoxication. In: Marrs, T.C., Maynard, R.L. and Sidell, F.R., Eds., Chemical Warfare Agents. Toxicology and Treatment, 2nd Edition, Wiley, Chichester, 331-342. https://doi.org/10.1002/9780470060032.ch16

[49] Schittkowski, M.P. and Sturm, V. (2018) Atropin zur Prävention der Myopieprogression-Datenlage, Nebenwirkungen, praktische Empfehlungen [Atropine for the Prevention of Progression in Myopia-Data, Side Effects, Practical Guidelines]. Klinische Monatsblatter fur Augenheilkunde, 235, 385-391.

https://doi.org/10.1055/s-0043-121982

[50] Chia, A., Chua, W.H., Cheung, Y.B., Wong, W.L., Lingham, A., Fong, A. and Tan, D. (2012) Atropine for the Treatment of Childhood Myopia: Safety and Efficacy of $0.5 \%, 0.1 \%$, and $0.01 \%$ doses (Atropine for the Treatment of Myopia 2). Ophthalmology, 119, 347-354. https://doi.org/10.1016/j.ophtha.2011.07.031

[51] Simon, G.A., Tirosh, M.S. and Edery, H. (1976) Administration of Obidoxime Tablets to Man. Plasma Levels and Side Reactions. Archives of Toxicology, 36, 83-88. https://doi.org/10.1007/BF00277566

[52] Baiomy, A.A., Attia, H.F., Soliman, M.M. and Makrum, O. (2015) Protective Effect of Ginger and Zinc Chloride Mixture on the Liver and Kidney Alterations Induced by Malathion Toxicity. International Journal of Immunopathology and Pharmacology, 28, 122-128. https://doi.org/10.1177\%2F0394632015572083 
[53] Yazdinezhad, A., Abbasian, M., Hojjat Hosseini, S., Naserzadeh, P., Agh-Atabay, A. H. and Hosseini, M.J. (2017) Protective Effects of Ziziphora tenuior Extract against Chlorpyrifos Induced Liver and Lung Toxicity in Rat: Mechanistic Approaches in Subchronic Study. Environmental Toxicology, 32, 2191-2202.

https://doi.org/10.1002/tox.22432

[54] Ibrahim, K.A., Khwanes, S.A., El-Desouky, M.A. and Elhakim, H. (2019) Propolis Relieves the Cardiotoxicity of Chlorpyrifos in Diabetic Rats via Alleviations of Paraoxonase-1 and Xanthine Oxidase Genes Expression. Pesticide Biochemistry and Physiology, 159, 127-135. https://doi.org/10.1016/j.pestbp.2019.06.006

[55] Yavuz, T., Altuntas, I., Delibas, N., Yildirim, B., Candir, O., Corâ, A., Karahan, N., Ibrisim, E. and Kutsal, A. (2004) Cardiotoxicity in Rats Induced by Methidathion and Ameliorating Effect of Vitamins E and C. Human \& Experimental Toxicology, 23, 323-329. https://doi.org/10.1191\%2F0960327104ht456oa

[56] Ramadan, G., El-Beih, N.M. and Ahmed, R.S. (2017) Aged Garlic Extract Ameliorates Immunotoxicity, Hematotoxicity and Impaired Burn-Healing in Malathionand Carbaryl-Treated Male Albino Rats. Environmental Toxicology, 32, 789-798. https://doi.org/10.1002/tox.22279 